\title{
Correction to: The role of an invader in its native range: could differential grazing by apple snails structure the submersed macrophytes assemblages in Southern Pampas (Argentina)?
}

\author{
Enzo Manara • Mara A. Maldonado • Pablo R. Martín
}

Published online: 22 November 2018

(C) Springer Nature Switzerland AG 2018

\section{Correction to: Hydrobiologia https://doi.org/10.1007/s10750-018-3815-5}

Due to an unfortunate turn of events, the surname of the first author appeared incorrectly in the original publication as it should have read Manara. The original article has been corrected and the proper representation of the authors' names and their affiliation is also listed here.

The original article can be found online at https:// doi.org/10.1007/s10750-018-3815-5.

E. Manara - M. A. Maldonado - P. R. Martín ( $\square)$ INBIOSUR (Universidad Nacional del Sur - Consejo Nacional de Investigaciones Científicas y Técnicas), San Juan 671, 8000 Bahía Blanca, Argentina e-mail: pablorafaelmartin@gmail.com

P. R. Martín

Laboratorio de Ecología, Departamento de Biología,

Bioquímica y Farmacia - Universidad Nacional del Sur,

San Juan 670, 8000 Bahía Blanca, Argentina 